\title{
Economic sustainability modeling provides decision support for assessing hybrid poplar-based biofuel development in California
}

by Varaprasad Bandaru, Nathan C. Parker, Quinn Hart, Mark Jenner, Boon-Ling Yeo, Jordan T. Crawford, Yuanzhe Li, Peter W. Tittmann, Luke Rogers, Stephen R. Kaffka and Bryan M. Jenkins

Biofuels are expected to play a major role in meeting California's long-term energy needs, but many factors influence the commercial viability of the various feedstock and production technology options. We developed a spatially explicit analytic framework that integrates models of plant growth, crop adoption, feedstock location, transportation logistics, economic impact, biorefinery costs and biorefinery energy use and emissions. We used this framework to assess the economic potential of hybrid poplar as a feedstock for jet fuel production in Northern California. Results suggest that the region has sufficient suitable croplands (2.3 million acres) and nonarable lands (1.5 million acres) for poplar cultivation to produce as much as 2.26 billion gallons of jet fuel annually. However, there are major obstacles to such large-scale production, including, on nonarable lands, low poplar yields and broad spatial distribution and, on croplands, competition with existing crops. We estimated the production cost of jet fuel to be $\$ 4.40$ to $\$ 5.40$ per gallon for poplar biomass grown on nonarable lands and $\$ 3.60$ to $\$ 4.50$ per gallon for biomass grown on irrigated cropland; the current market price is $\$ 2.12$ per gallon. Improved poplar yields, use of supplementary feedstocks at the biorefinery and economic supports such as carbon credits could help to overcome these barriers.

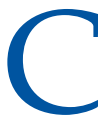
alifornia policies designed to reduce greenhouse gas emissions are creating a new economic reality for in-state bioenergy production through the cap and trade program, the low carbon fuel standard (LCFS) program,

Senate Bill 1122, which requires that utilities procure at least 250 megawatts of bioenergy, and increasingly stringent renewable portfolio standards. Assembly
Bill 32 sets a goal of reducing greenhouse gas emissions in the state to 1990 levels by 2020, while the LCFS program aims to reduce transportation fuel carbon intensity by $10 \%$ to achieve those targets. In addition, an executive order issued by Gov. Jerry Brown in April 2015 calls for an 80\% reduction in greenhouse gas emissions statewide by 2050 . Locally produced renewable energy sources such as biomassderived fuels have the potential to help achieve these goals and meet California's energy needs (Jenkins et al. 2009; Morrison et al. 2014; Youngs and Somerville 2013).

Numerous cellulosic biomass resources are potentially available for biofuel production in California, including crop residues (e.g., rice and wheat straw), perennial grasses (e.g., switchgrass [Pennisetum purpureum]), forest residues (e.g., logging slash and forest thinnings), and wood

Online: http://californiaagriculture.ucanr.edu/

landingpage.cfm?article=ca.v069n03p171\&fulltext=yes

doi: 10.3733/ca.v069n03p171

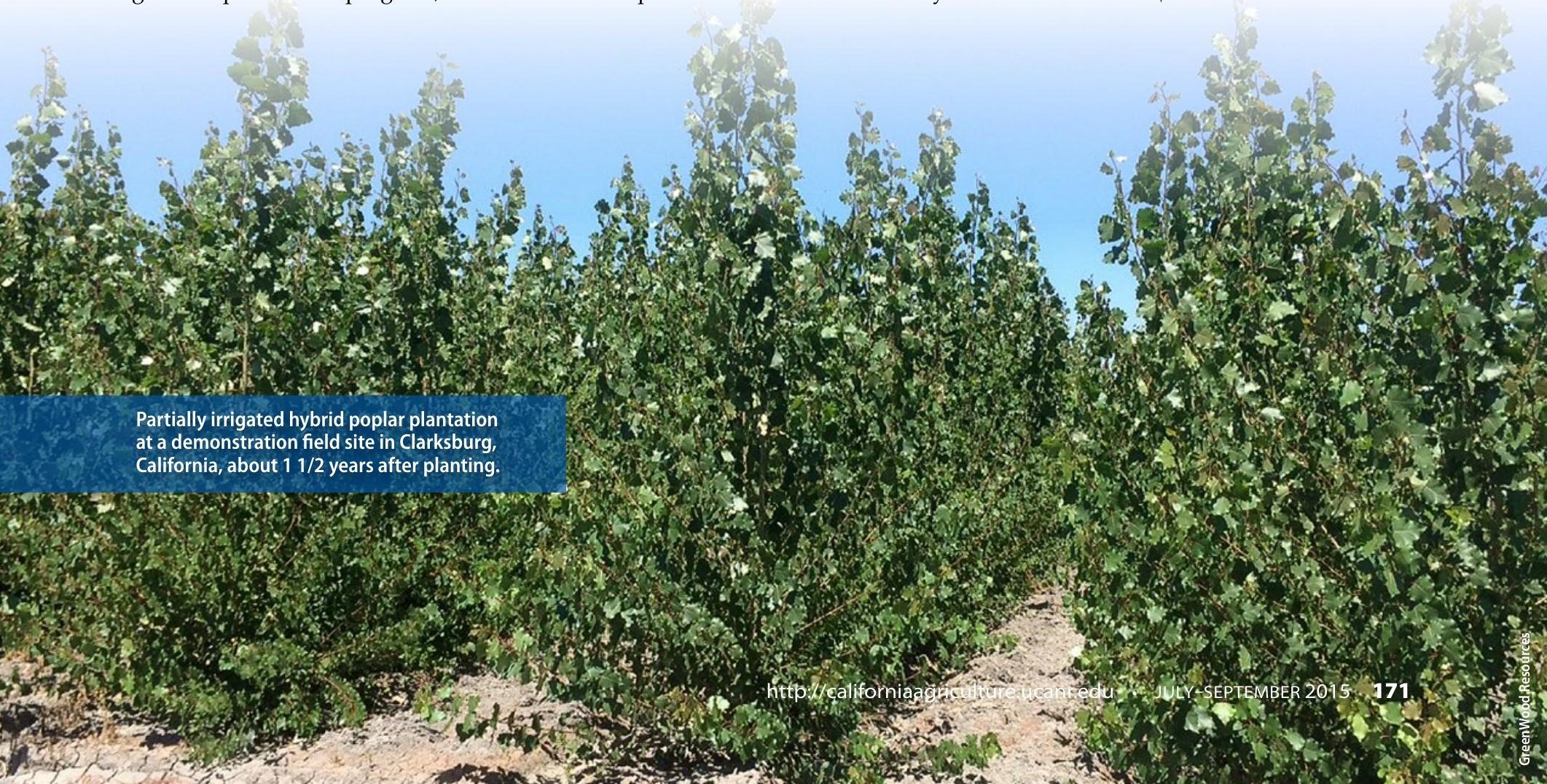


chips from dedicated energy crops (e.g., hybrid poplar [Populus spp.], willow [Salix spp.] and eucalyptus [Eucalyptus spp.]) (Youngs and Somerville 2013).

Hybrid poplar is a widely studied short rotation (harvested frequently) woody crop that not only can serve as a feedstock for biofuel production, but also can offer multiple ecological benefits including carbon sequestration - in amounts ranging from 0.2 to 0.7 tons carbon per acre per year in the topsoil (Baum et al. 2009; Garten 2002) - restoration of degraded lands such as former mining sites (Werner et al. 2012), stream protection from agricultural runoff, and habitat for wildlife (Ugarte et al. 2003). Due to its rapid growth and suitability for coppicing (harvesting trees near ground level and allowing the trees to resprout for the subsequent growth interval), poplar has the ability to provide a flexible and consistent supply of biomass for biofuel production (Yemshanov and McKenney 2008). Ease of propagation and interspecies hybridization will likely facilitate the development of hybrid genotypes that are highly productive and suitable for a wide variety of soil and climatic conditions (Wang et al. 2013).

In addition, earlier studies have suggested that hybrid poplar can be grown on various lands (e.g., marginal lands) and that its growth depends on soil productivity and management (Netzer et al. 2010; Pearson et al. 2010; Xue et al. 2014). The average water requirement for trees 3 years or older is approximately 45 acre-inches/acre in a semi-arid environment (Shock et al. 2002), which implies that in drier regions, irrigation may be required to ensure plant survival and reasonable yields.

Although poplar is already recognized as a potential feedstock source for low-carbon biofuel production, commercial deployment is not yet realized due in part to economic conditions (e.g., net revenue constraints) and uncertainties about resource availability (e.g., land and water resources for poplar

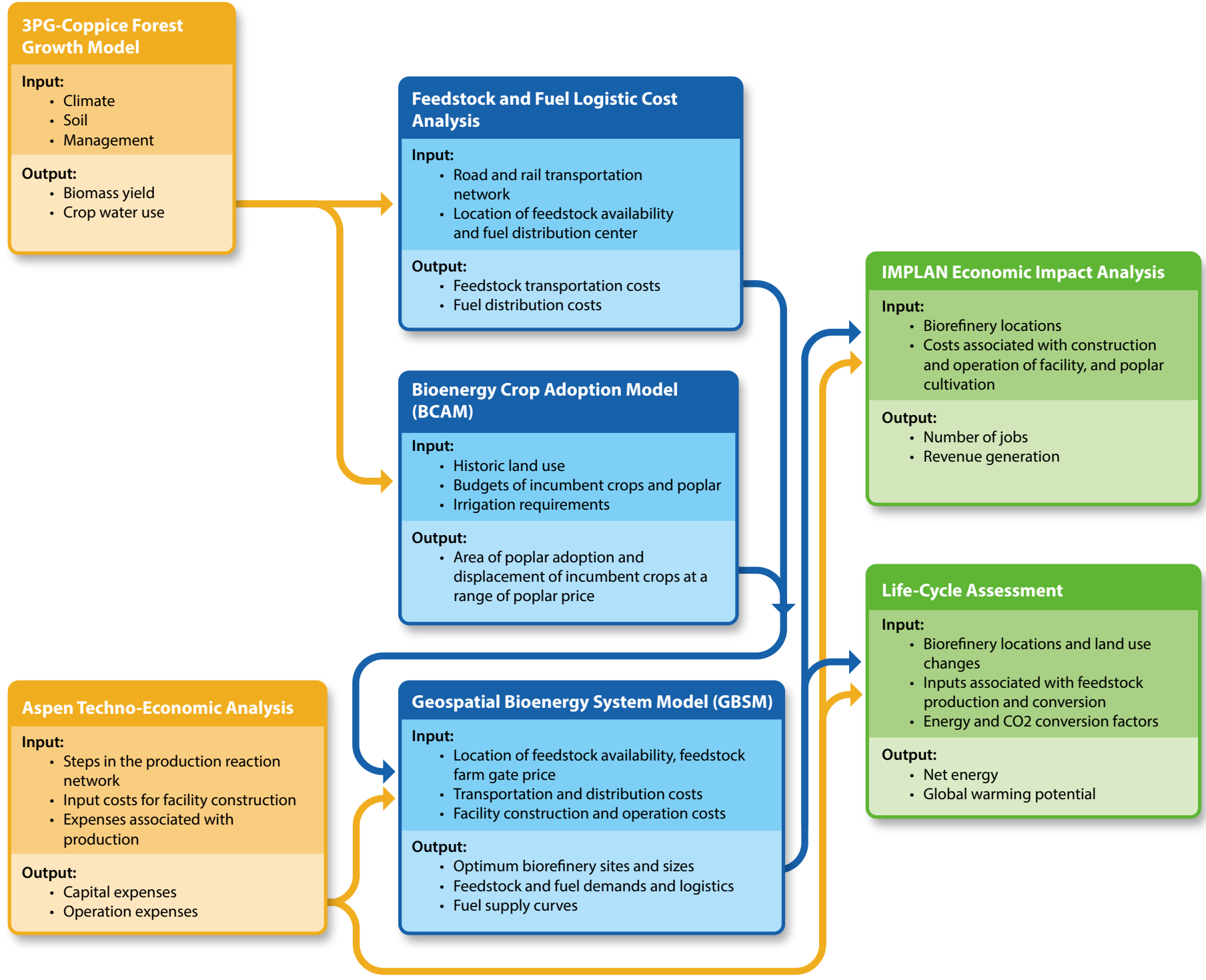

Fig. 1. Integrated modeling framework used to assess the feasibility of poplar-based biofuel in Northern California. This framework consists of models and commercial software to assess various sustainability aspects related to poplar-based biofuel industry development. The arrows reflect the flows of data from model to model. 
cultivation). As part of a larger research and development initiative in the Pacific Northwest on sustainable production of biofuel from poplar (for details, visit hardwoodbiofuels.org), we used an integrated modeling framework comprised of multiple models (fig. 1) to assess the potential for poplar-based biofuel industries in a region comprised of 32 counties in Northern California (fig. 2). In this study, we evaluated poplar-based jet fuels, hydrocarbon fuels that meet current fuel quality specifications and are compatible with the existing infrastructure for handling and using petroleumbased fuels.

Aviation grade biofuels are particularly interesting because they are the only near-term option for low-carbon aircraft propulsion that does not require a complete redesign of aircraft. Over the longer term, other renewable energy carriers such as hydrogen and electricity may emerge if aircraft are developed to utilize those fuels. Liquid fuels generated from sunlight are another promising alternative that is currently in the laboratory development stage, e.g., methanol synthesis from carbon dioxide and water (Fairley 2011).

\section{Modeling approach}

The framework integrates seven models that represent the elements of a poplar-based biofuel supply chain (fig. 1): feedstock production, optimization of biofuel production, facility-specific technical and economic performance, transportation network costs and life-cycle environmental and economic impacts. The framework includes (1) the 3PGCoppice growth model, (2) the Bioenergy Crop Adoption Model (BCAM), (3) the Geospatial Bioenergy System Model (GBSM), (4) feedstock and fuel logistics cost analysis, (5) Aspen Plus technoeconomic modeling software, (6) IMPLAN social and economic impact analysis software and (7) SimaPro life-cycle assessment software. BCAM and GBSM were developed at UC Davis. 3PG-Coppice was also developed at UC Davis as a modification of the original Physiological Principles in Predicting Growth (3PG) forest growth model created by Landsberg and Waring (1997) that did not allow for coppicing of the crop. The other models in the framework are commercially available products.

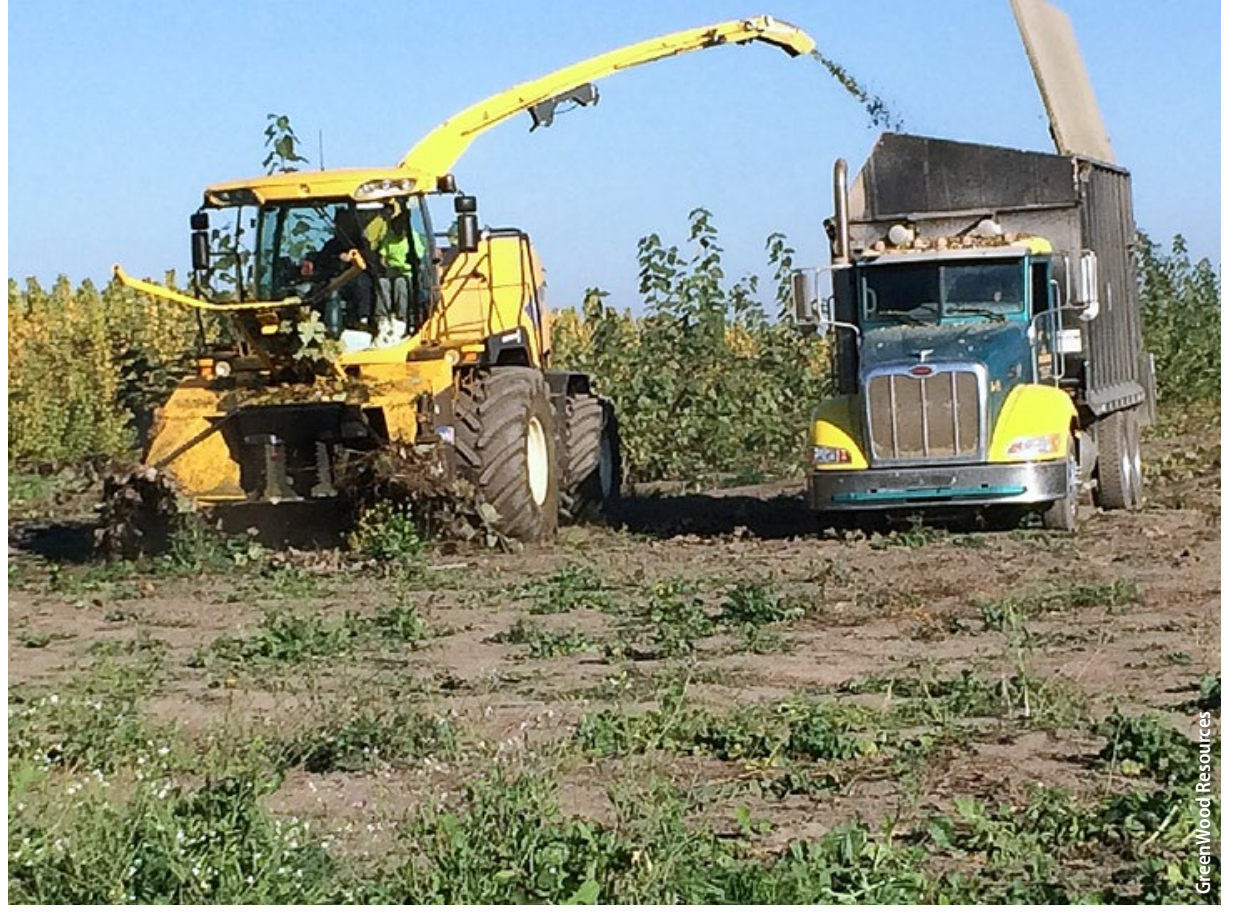

Harvesting hybrid poplar at a demonstration site in Clarksburg, CA.

Poplar biomass yield. We used the 3PGCoppice model to predict potential yields of poplar biomass on available lands. When poplar is grown as a short rotation crop, coppicing facilitates multiple harvests during the production cycle. However, since the original 3PG model does not include algorithms for coppicing regrowth, we included a coppicing submodule to account for the root contribution to stem regrowth after harvesting (Prilepova et al. 2014).

Transportation costs. Where poplar biomass is produced influences the economic performance of refineries, as biomass collection and transportation costs depend on the location of feedstock production relative to the refinery site and the amount of feedstock demanded. To calculate the transportation costs for biomass, feedstock logistics data were applied within a GIS network analysis utilizing cost values from the literature for different transport modes (truck, rail and barge) (Parker et al. 2010).

Crop adoption. To be adopted by growers, poplar produced on croplands must economically outperform other crops. BCAM was used to examine the potential for poplar to compete with existing crops. BCAM is a whole-farm economic profit maximization model based on Positive Mathematical Programming optimization principles (Jenner and Kaffka 2012).
It uses production budgets for hybrid poplar estimated from simulated biomass yields along with budgets for current crops with yields from U.S. Department of Agriculture (USDA) National Agricultural Statistics Service (USDA 2010) historical data, and it computes crop shifting and area of poplar adoption at different market prices in a given region based on profit levels.

Biofuel industry optimization. GBSM is a spatially explicit optimization model developed using mixed-integer linear programming principles (Parker et al. 2010). The model considers the entire biofuel supply chain (i.e., distribution of biomass resources, costs associated with biomass production and harvesting, transportation costs of biomass supply to the refinery, and capital and operating costs of biorefineries as a function of size) and determine the optimal sites for the refineries based on maximizing overall profit. The capital and operating costs of biorefineries used in GBSM were estimated using a techno-economic model created in the process simulation software Aspen Plus (AspenTech 2011) and process-specific information regarding the conversion of biomass to fuel (Crawford 2013).

Environmental and economic impacts. The data from GBSM on optimum refinery sites and spatial land use change, and bioconversion data from Aspen Plus, were 
used in SimaPro v.7.3.3 (PRé Consultants 2012) to assess environmental impacts of poplar production. The socioeconomic impacts (e.g., job creation, revenue generation) at regional and state levels were analyzed using IMPLAN software. Results on the environmental and socioeconomic impacts are preliminary and are not discussed further here pending further analysis.

\section{Potential poplar cultivation sites}

We used land quality metrics and 2009 USDA land use and land cover data

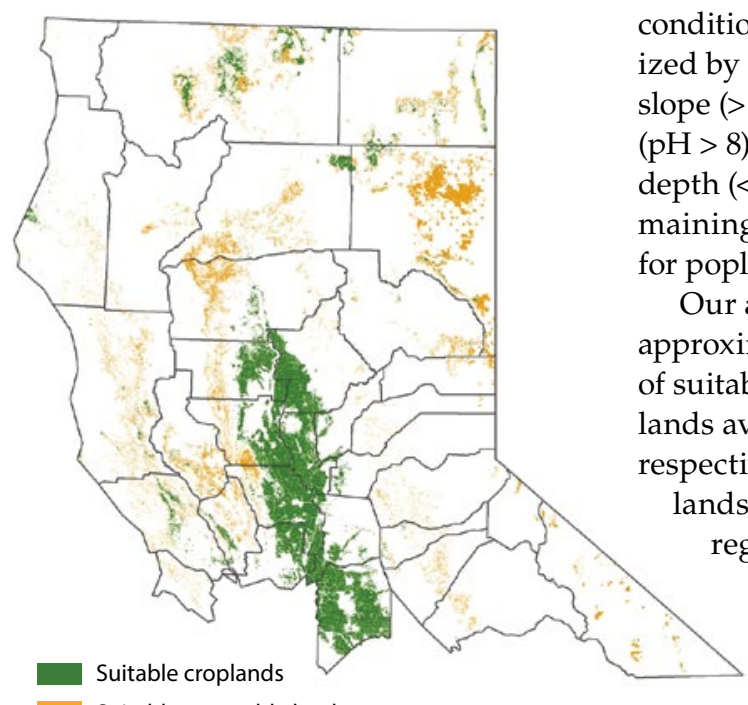

Suitable nonarable lands

Fig. 2. Available croplands and nonarable lands (nonirrigated pasture and grasslands) in the study region (32 counties in Northern California) suitable for poplar cultivation under model analysis. Black lines represent county boundaries.

\section{Irrigated croplands and nonarable lands in Northern California have the potential to provide 18.9 and 7.1 million dry tons of poplar feedstock annually, which could result in 1,648 and 618 million gallons of jet fuel per year.}

(Johnson and Mueller 2010) to identify potential nonarable lands (pasture and grasslands) and croplands for poplar cultivation in the study region, then used the 3PG-Coppice model to estimate the inherent biomass yield potentials on these locations under irrigated and nonirrigated conditions. Lands that were characterized by soil salinity $(>4.0 \mathrm{dS} / \mathrm{m})$, steeper lope $(>15 \%)$, acidity $(\mathrm{pH}<4.0)$, alkalinity $\mathrm{pH}>8)$ and shallow soil and water table epth ( $<20$ inches) were excluded and reing soils were considered as suitable pultivation.

Our analysis showed that there are approximately 2.3 and 1.5 million acres of suitable croplands and nonarable ands available in Northern California, respectively. While suitable nonarable

lands are scattered widely across the region, croplands are mostly concentrated in the Central Valley (fig. 2). Simulated biomass growth suggests that biomass potential varies substantially across the study region and ranges from 1.5 to 14.1 dry tons/acre per year depending on location, land type, climatic conditions and management (fig. 3). Irrigated croplands result in considerably

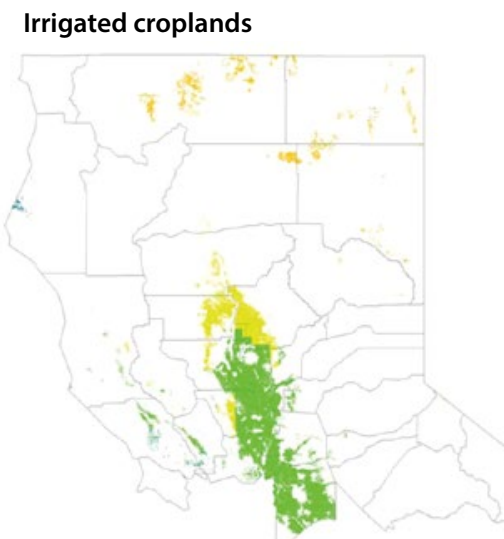

Nonirrigated nonarable lands

Biomass (dry ton acre $\mathrm{y}^{-1} \mathrm{y}^{-1}$ )

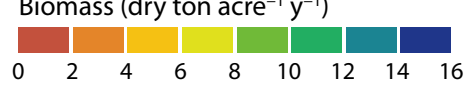

Fig. 3. Spatial estimates of poplar biomass yields (dry tons per acre per year) from suitable irrigated croplands and nonarable lands (nonirrigated pasture and grasslands). higher yields (on average $44 \%$ ) than nonarable lands (which are not irrigated) with spatial averages of 8.2 and 4.6 dry tons/acre per year, respectively (fig. 3).

Overall, irrigated croplands and nonarable lands in Northern California have the potential to provide 18.9 and 7.1 million dry tons of poplar feedstock annually, which could result in 1,648 and 618 million gallons of jet fuel per year based on projected fuel yields of 80 gallons per dry ton of biomass feedstock (Crawford 2013). However, it is important to recognize that the actual amount of biomass available for biofuel production and amount of jet fuel produced depend on many factors, such as the amount of available cropland that will be converted to poplar cultivation.

\section{Economics of poplar production}

Higher profits from poplar cultivation compared to other feasible crops are needed for landowners to adopt hybrid poplar for bioenergy purposes. We evaluated the economics of poplar production on both irrigated croplands and nonarable lands.

We estimated that the average poplar production cost (not including transport to the biorefinery) on nonarable lands in Northern California is $\$ 74 /$ dry ton; for irrigated croplands, the average cost is $\$ 53 /$ dry ton, due mostly to higher yields and lower establishment costs. Even though the production cost for irrigated croplands is lower than that for nonirrigated lands, the opportunity costs of displacing other crops are likely to be much higher, as poplar must compete with existing crops and typically incurs a 20-year production commitment.

Nonarable lands. In the case of nonarable lands, the opportunity cost of land is less than on irrigated cropland; however, due to lower biomass yield potentials and higher production costs associated with establishment and harvesting, poplar production is on the whole less economically viable. In addition, the intermittent cash flow from 2- to 3-year harvesting cycles may discourage some landowners 
from growing poplar. Therefore, to make poplar production economically attractive on nonarable lands, substantial incentives may be required, such as the Biomass Crop Assistance Program (BCAP) (Schnepf 2014). Research efforts targeting plant breeding to develop high yielding varieties could help further by increasing the profitability of hybrid poplar on nonarable lands (Berguson et al. 2010), although water is likely to remain a critical constraint for such lands in California.

Irrigated croplands. Croplands in California are characterized by highly diversified farming systems comprising numerous high-value specialty crops such as vegetables, fruits and nuts, and field crops (e.g., rice, wheat, corn). As such, poplar will encounter significant competition from these cropping systems. The total potential for poplar adoption in a given region depends on local farming patterns. A region with a high number of lowervalue crops could witness a high fraction of poplar adoption. Economic analysis using BCAM indicates that hay followed by corn silage are the crops most likely to be displaced by poplar.

Another important observation is that the entry price (the market price at which poplar is likely to be adopted) will vary from region to region depending on the demand for existing crop commodities, poplar biomass potential and poplar production costs. For instance, BCAM results suggest that because of higher average yields, the north central region of California has a lower entry price (\$48/dry ton) for poplar adoption when compared to northwestern (\$54/dry ton) and northeastern California ( $\$ 69 /$ dry ton).

\section{Economics of potential biorefineries}

The financial performance of the biofuel industry is influenced by many factors, including the distribution of biomass resources, collection and transportation costs, and economies of scale associated with facility construction and operation (Leduc et al. 2010). The interactions among these factors and how they influence each other is important in determining the overall economic feasibility of the biofuel industry. We used GBSM to assess the economic efficiency of potential poplar-based jet fuel facilities in Northern California each with a production capacity of 100 million gallons per year (MGY). A total of 212 representative potential

facility sites were selected from a set of locations having existing industrial land or similar industrial facilities in the vicinity (figs. 4 and 5). Site-specific capital costs were based on the cost of adding infrastructure (such as building a rail spur to the site) and the value of industrial land at the location. Facility construction and operating costs were based on data from the ZeaChem demonstration

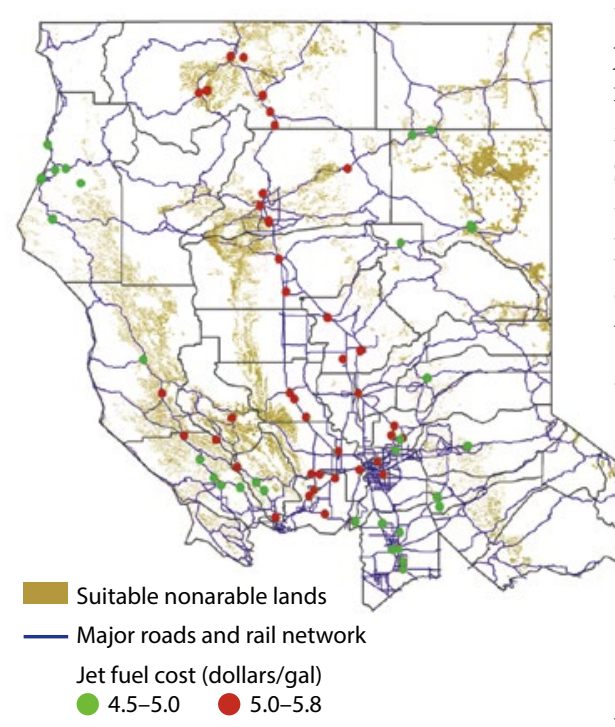

Fig. 4. Possible sites for independent 100-milliongallon per year (MGY) biorefineries in Northern California and optimum jet fuel price for each site based on biomass supply from suitable nonarable lands (nonirrigated pasture and grasslands).

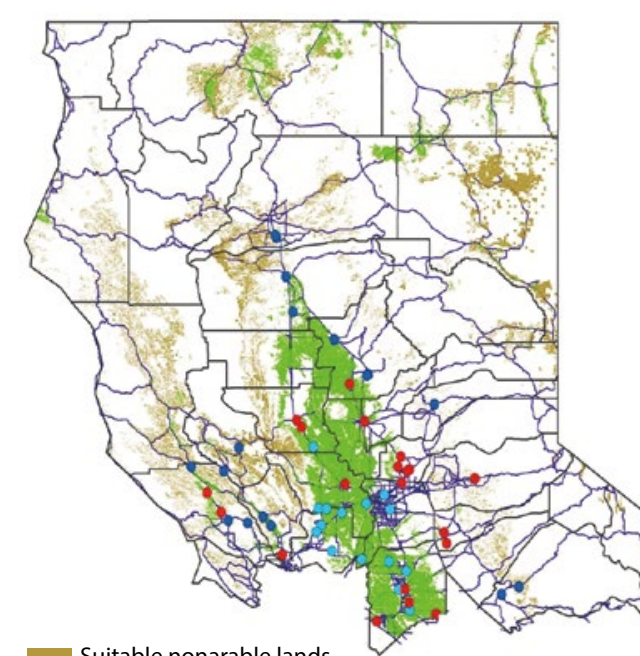

Suitable nonarable lands Suitable croplands Major roads and rail network

Jet fuel cost (dollars/gal)

4.04-4.15 4.15-4.27

$4.27-4.38$

Fig. 5. Possible sites for independent 100-milliongallon per year (MGY) biorefineries in Northern California and optimum jet fuel price for each site based on biomass supply from both suitable croplands and nonarable lands (nonirrigated pasture and grasslands). biorefinery at Boardman, Oregon (Verser and Eggeman 2011), which was designed with a production yield of approximately 80 gallons of jet fuel from each dry ton of biomass feedstock.

As mentioned earlier, suitable nonarable lands in Northern California are widely scattered across the region and are characterized by lower biomass yields. These factors lead to substantially higher biomass acquisition and transportation costs and impact the final cost of jet fuel. GBSM results indicate that for nonarable lands, the average jet fuel price from an optimized 100-MGY facility is $\$ 4.90 /$ gallon, or about $\$ 2.78 /$ gallon higher than current jet fuel price (U.S. Energy Information Administration 2015). An analysis of sensitivity to poplar yield, harvest cost and biorefinery capital cost suggests a range of optimized costs between

$\$ 4.40$ and $\$ 5.40$ per gallon (average plus or minus one standard deviation). Thus, under current market conditions, poplar from nonarable lands alone may not be enough to support a poplarbased biofuel industry.

When suitable croplands are considered along with nonarable lands for poplar production, jet fuel might be produced at a significantly lower cost $-\$ 3.60$ to $\$ 4.50$ per gallon with an expected value of $\$ 4.04 /$ gallon - but one that is still above the current market price.

The estimate of adopted croplands for this analysis is strictly economic, but a number of other elements, including social (e.g., individual perceptions, environmental justice) and regulatory factors (e.g., environmental policies), also influence the adoption of new crops. As such, there remains substantial uncertainty as to how much cropland might realistically shift to poplar production. In future

work, we plan to use the life-cycle analysis and IMPLAN models to develop a clearer picture of the prospects for poplar as a viable biofuel crop.

\section{Conclusions}

Even though there is a reasonable amount of suitable nonarable land available, lower biomass yields on nonirrigated land and the dispersed geographic distribution of suitable lands are major barriers to 
Even though there is a reasonable amount of suitable nonarable land available, lower biomass yields on nonirrigated land and the dispersed geographic distribution of suitable lands are major barriers to poplar adoption.

poplar adoption. Continuing research efforts to improve poplar biomass yields may be able to reduce production costs. Developing technology that utilizes additional biomass resources such as crop residues (e.g., wheat straw, rice straw) and forest residues for jet fuel at the same facility could improve prospects for the biofuel industry. Poplar feedstock also can be used to produce other bio-based products (e.g., organic chemicals, adhesives) that may be economically more promising due to the lower costs of feedstock conversion and higher value in the marketplace.

Policy measures, particularly higher value carbon credits, could also improve prospects for a larger biofuel industry in California. Companion research from the
University of Washington indicates that the global warming potential of poplarbased jet fuels produced using lignin gasification technology is $27 \%$ to $71 \%$ lower than that of petroleum-based jet fuels. Thus, carbon credits could help a poplar-based jet fuel industry to become an economically competitive alternative. The modeling framework outlined here is designed to provide important decision support capacity in the analysis of agronomic, technology and policy alternatives not only for biofuel production, but for other resource management questions, including crop and livestock development, and soil and water conservation, more generally. CA
V. Bandaru is Project Scientist and N.C. Parker is Postdoctoral Researcher in the UC Davis Energy Institute; Q. Hart is Programmer in the Department of Land, Air and Water Resources at UC Davis; M. Jenner is Biomass Systems Economist and B.L. Yeo is Postdoctoral Research Associate in the Department of Plant Sciences at UC Davis; J.T. Crawford is Graduate Research Assistant in the School of Environmental and Forest Sciences at University of Washington; Y. Li is Graduate Student Researcher in the Department of Civil and Environmental Engineering at UC Davis; P.W. Tittmann is Geographer in the UC Berkeley Center for Forestry; L. Rogers is Research Scientist in the School of Environmental and Forest Sciences at University of Washington; S.R. Kaffka is UC ANR Cooperative Extension Specialist in the Department of Plant Sciences at UC Davis; and B.M. Jenkins is Professor in the Department of Biological and Agricultural Engineering at UC Davis.

\section{References}

AspenTech. 2011. Aspen Plus user guide (v7.3). Burlington, MA.

Berguson B, Eaton J, Stanton B. 2010. Development of hybrid poplar for commercial production in the United States: The Pacific Northwest and Minnesota experience. In: Braun R, Karlen D, Johnson D (eds.). Sustainable Alternative Fuel Feedstock Opportunities, Challenges and Roadmaps for Six U.S. Regions. Ankeny, IA: Soil and Water Conservation Society. p 282-99.

Baum C, Leinweber P, Weih M, et al. 2009. Effects of short rotation coppice with willows and poplar on soil ecology. Landbauforsch vTI Ag 3:183-96.

Crawford JT. 2013. Techno-economic analysis of hydrocarbon biofuels from poplar biomass. Master's thesis, University of Washington. https://digital.lib.washington edu/researchworks/handle/1773/25142 (accessed March 16, 2014).

Fairley P. 2011. Next generation biofuels. Nature 474:S2-5. Garten Jr. CT. 2002. Soil carbon storage beneath recently established tree plantations in Tennessee and South Carolina, USA. Biomass Bioenerg 23:93-102. Jenkins B, Williams R, Parker N, et al. 2009. Sustainable use of California biomass resources can help meet state and national bioenergy targets. Calif Agr 63:168-77.

Jenner M, Kaffka S. 2012. California Energy Commission Draft Report: Energy Crop Assessement in California Using Optimization Modeling. http://energy.ucdavis. edu/files/05-13-2013-3-2-1-1-energy-crops-and-residueassessment.pdf (accessed April 22, 2014). 34 p. Johnson DM, Mueller R. 2010. The 2009 cropland data layer. Photogramm Eng Rem S 76: 1201-5.

Landsberg J, Waring R. 1997. A generalized model of forest productivity using simplified concepts of radiationuse efficiency, carbon balance and partitioning. Forest Ecol Manag 95: 209-28.
Leduc S, Starfelt F, Dotzauer E, et al. 2010. Optimal location of lignocellulosic ethanol refineries with polygeneration in Sweden. Energy 35: 2709-16.

Morrison G, Eggert A, Yeh S, et al. 2014. Summary of California Climate Policy Modeling Forum. http://ssrn.com/ abstract=2401929 (accessed September 19, 2014).

Netzer M, Goslee K, Pearson TRH, Brown S. 2010. Opportunity Assessment for Establishing Hybrid Poplars in California, Oregon and Washington. California Energy Commission, PIER program. 500-2014-044. http://uc-ciee. org/downloads/30_Poplars\%20CA_OR_WA.pdf (accessed July 12, 2015). $58 \mathrm{p}$.

Parker N, Tittmann P, Hart Q, et al. 2010. Development of a biorefinery optimized biofuel supply curve for Western United States. Biomass Bioenerg 34:1597-1607.

Pearson CH, Halvorson AD, Moench RD, Hammon RW. 2010. Production of hybrid poplar under short-term, intensive culture in Western Colorado. Ind Crop Prod 31:492-98.

PRé Consultants. 2012. SimaPro 7 (v.7.3.3). Amersfoort, Netherlands.

Prilepova O, Hart Q, Merz J, et al. 2014. Design of a GISbased web application for simulating biofuel feedstock yields. ISPRS Int J Geo-Inf 3:929-41.

Shock CC, Beibert EBG, Seddigh M, Saunders LD. 2002. Water requirements and growth of irrigated hybrid poplar in a semi-arid environment in eastern Oregon. West J Appl For 17:46-53.

Schnepf R. 2014. Biomass Crop Assistance Program (BCAP): Status and Issues. Washington, DC: Congressional Research Service. http://nationalaglawcenter.org/wpcontent/uploads/assets/crs/R41296.pdf (accessed June 10, 2014). 20 p.

Ugarte DG, Walsh ME, Shapouri H, Slinsky P. 2003. The economic impacts of bioenergy crop production in US agriculture. USDA Agricultural Economic Report No. 816. Washington, DC: USDA. 49 p.
[USDA] US Department of Agriculture. 2010. Quick Stats, U.S. \& All States County Data-Crops. Washington, DC: USDA National Agricultural Statistics Service. http:// quickstats.nass.usda.gov/ (accessed April 1, 2014). US Energy Information Administration. 2015. Annual crude oil and jet fuel prices. California kerosene-type jet fuel retail sales by refiners (dollars per gallon). www.eia. gov/dnav/pet/hist/LeafHandler.ashx? n=PET\&s=EMA EPJK_PTG_SCA_DPG\&f=M (accessed August 9, 2015).

Verser D, Eggeman TJ. 2011 . Process for producing ethanol. US Patent 7,964,379 B2, filed Jan 26, 2010. ZeaChem, Inc. www.google.com/patents/US7964379.

Wang D, LeBauer D, Dietze M. 2013. Predicting yields of short-rotation hybrid poplar (Populus spp.) for the United States through model-data synthesis. Ecol App 23: 944-58.

Werner C, Haas E, Grote R, et al. 2012. Biomass production potential from Populus short rotation systems in Romania. GCB Bioenerg 4: 642-53.

Xue Z, Qu LQ, Yang XS. 2014. Potential production and spatial distribution of hybrid poplar as a biofuel crop in Connecticut, USA. Int J Agric Biol Eng 7:10-18.

Yemshanov D, McKenney DW. 2008. Fast-growing poplar plantations as a bioenergy supply source for Canada. Biomass Bioenerg 32:185-97.

Youngs H, Somerville CR. 2013. California's Energy Future - The Potential for Biofuels. California Council on Science and Technology report. http://www.ccst.us/ news/2013/0531 cef.php (accessed April 3, 2014). 